\title{
Incorporation of flexible ionic polymers into a Lewis acid-functionalized mesoporous silica for cooperative conversion of $\mathrm{CO}_{2}$ to cyclic carbonates
}

\author{
Ruqun Guan, Xiaoming Zhang *, Fangfang Chang, Nan Xue, Hengquan Yang \# \\ School of Chemistry and Chemical Engineering, Shanxi University, Taiyuan 030006, Shanxi, China
}

\section{A R T I C L E I N F O}

Article history:

Received 5 February 2019

Accepted 25 March 2019

Published 5 December 2019

\section{Keywords:}

Mesoporous silica

Flexible ionic polymer

Cooperative effects

$\mathrm{CO}_{2}$ utilization

Heterogeneous catalysis

\begin{abstract}
A B S T R A C T
A rational integration of multiple reactive centers into a combined unit to facilitate their cooperative effects is a smart approach for accelerating the catalytic activity. Here, to achieve this goal, linear imidazolium-based ionic polymers were confined into the nanopores of mesoporous silica nanospheres anchored with homogeneously distributed zinc salts. Owing to the flexible character and the reinforced cooperative effects of the ionic liquid (nucleophile) and zinc species (Lewis acid) in the confined mesoporous structure, the resultant composite exhibited dramatically improved catalytic performance in the cycloaddition of $\mathrm{CO}_{2}$ with epoxides to form cyclic carbonates. This was in contrast to that observed for the individual catalytic components. Moreover, such a solid catalyst could be easily recovered and reused four times without a significant loss of activity.
\end{abstract}

(C) 2019, Dalian Institute of Chemical Physics, Chinese Academy of Sciences. Published by Elsevier B.V. All rights reserved.

\section{Introduction}

As an important and promising chemical fixation pathway of carbon dioxide $\left(\mathrm{CO}_{2}\right)$, its cycloaddition with epoxides to form cyclic carbonates has attracted considerable attention in recent years owing to its excellent merits, including high atom economy, green reaction, and the versatile application in the syntheses of cyclic carbonates [1-6]. Various kinds of homogeneous catalysts such as metal complexes [7-9], metal salts [10], $N$-heterocyclic carbenes [11], and ionic liquids (ILs) [12-14] and heterogeneous catalysts such as metal oxides [15], metal-organic frameworks (MOFs) [16-18], porous organic polymers [19-21], and $N$-doped carbons [22] have been developed for this transformation. Among these catalysts, environmental- ly friendly ILs are found to be a good candidate for both $\mathrm{CO}_{2}$ capture and fixation, and various ILs have been produced [23-27]. Although these IL-based homogeneous catalytic systems are efficient, their complex recycling processes, high viscosity, and relatively low utilization efficiency severely impede their industrial applications.

To overcome these existing problems, ILs are generally immobilized on different solid materials (e.g., silica [28-30], polymer [31-34], and MOFs [35,36]), forming heterogeneous catalysts. However, a low catalytic efficiency is often encountered for the heterogeneous systems because of the loss of active sites after immobilization. A Lewis acid is required to form Lewis acid/ionic liquid catalytic system, because the synergetic catalytic effect between the Lewis acid and nucleophile could

\footnotetext{
* Corresponding author. Tel: +86-351-7011588; Fax: +86-351-7011688; E-mail: xmzhang4400@sxu.edu.cn

\# Corresponding author. Tel: +86-351-7011588; Fax: +86-351-7011688; E-mail: hqyang@sxu.edu.cn

This work was supported by the National Natural Science Foundation of China (201573136, 21603128, U1510105), the Natural Science Foundation for Young Scientists of Shanxi Province (2016021034), and the Scientific Research Start-up Funds of Shanxi University (RSC723). DOI: S1872-2067(19)63340-1 | http://www.sciencedirect.com/science/journal/18722067 | Chin. J. Catal., Vol. 40, No. 12, December 2019
} 
significantly promote the reaction [12]. Therefore, from a mechanistic point of view, the conventional immobilization methods, which result in the spatial separation of active sites within the rigid framework, will certainly block the dual activation mode. However, it is still highly desirable to develop IL-based heterogeneous catalysts that can promote the cooperative effects of the different active sites, for the $\mathrm{CO}_{2}$ cycloaddition reactions.

Recently, it was found that the cooperative catalytic effects could be greatly enhanced through proper arrangement of the different active species in close proximity within a confined nanospace [35-43]. Especially, linear macromolecular ionic polymers with flexible and soluble properties were confined instead of IL catalysts. By doing so, not only the "free" state, similar to their homogeneous counterparts, could be maintained during reaction, but also an extraordinary recyclability could be obtained due to the existing twining effect of the long chain linear polymers with large molecular weight [37,44]. Furthermore, while utilizing Lewis acid-doped porous support as the host material, the cooperative effect between the heterogeneous Lewis acid sites and poly-ILs can be enhanced, thus leading to a superior catalytic system. To date, different porous structures, including covalent organic frameworks [37] and metal organic frameworks $[35,36]$, have been investigated to accommodate linear ionic polymer catalysts and promote the cooperative effects. In addition to these porous materials, there are also other promising candidates that can be utilized as a host matrix. Ordered mesoporous materials, possessing well-defined pore structures, controlled pore size $(2-50 \mathrm{~nm})$, and high surface area, for example, have attracted great attention in the last two decades [45-48]. Catalytically active guest species can either be loaded into its mesoporous network or be dispersed on the pore surface through grafting or a co-condensation process. Thus, a synergetic catalytic effect may work between the two different kinds of functional groups introduced.

In this study, we report the confinement of a linear imidazolium-based ionic polymer catalyst in the mesopores of ordered mesoporous silica nanospheres (MSN) that are pre-anchored with zinc species through in situ polymerization. Such a unique, active, and co-decorated solid species could efficiently catalyze the cycloaddition reaction of epoxides to form cyclic carbonates. It could also exhibit a much higher activity than its corresponding individual catalytic components. The superior catalytic activity is mainly attributed to the enhanced cooperative effect between the zinc species that acted as a Lewis acid and the ionic liquid that served as a nucleophile in the confined mesoporous structure.

\section{Experimental}

\subsection{Materials}

All the chemicals were used directly as received. Sodium hydroxide $(\mathrm{NaOH})$, cetyltrimethylammonium bromide (CTAB), tetraethyl orthosilicate (TEOS), propylene oxide (PO), and $\mathrm{ZnBr} 2$ were purchased from Shanghai Chemical Reagent Com- pany of the Chinese Medicine Group. 2-(4-Chlorosulphonylphenyl)ethyl trichlorosilane (CSPE) in methylene chloride (47-53 wt\%) was obtained from J\&K Scientific LTD. 2,2'-Azobisisobutyronitrile (AIBN) was purchased from Aladdin (China). Epichlorohydrin (99\%), 1,2-epoxybutane, styrene oxide, cyclohexene oxide, allyl glycidyl ether, and glycidyl phenyl ether were purchased from Beijing Innochem. 1-Vinyl-3-butylimidazolium bromide was prepared according to the method given in the literature [49].

\subsection{Preparation of mesoporous silica anchored with zinc species}

A certain amount of $\mathrm{NaOH}$ solution $(0.35 \mathrm{~mL}, 2 \mathrm{~mol} / \mathrm{L})$ was added to $45 \mathrm{~mL}$ water, in which $0.10 \mathrm{~g}$ CTAB was dissolved. After stirring at $70{ }^{\circ} \mathrm{C}$ for $15 \mathrm{~min}$, TEOS $(0.45 \mathrm{~g}$ ) was added to the mixture as a silane precursor and prehydrolyzed for about $5 \mathrm{~min}$. Then, CSPE in methylene chloride $(0.32 \mathrm{~g})$ was added dropwise to the system and stirred for another $2 \mathrm{~h}$ at $70^{\circ} \mathrm{C}$. The powder product was isolated by filtration and washed with water and ethanol. To remove the surfactant, the synthesized material was dispersed in $60 \mathrm{~mL}$ ethanol, in which $40 \mathrm{mg}$ ammonium nitrate was dissolved. After being treated at $60{ }^{\circ} \mathrm{C}$ for $0.5 \mathrm{~h}$, the solid material was isolated and washed with ethanol. Such a process was repeated thrice to remove the surfactant completely. As for the synthesis of the MSN without the zinc species, a similar procedure as above was performed, except that only TEOS, and no CSPE, was utilized as the silane precursor.

The above solid powder was dispersed into $5.0 \mathrm{~mL} \mathrm{ZnBr}_{2}$ (1.0 g) solution at room temperature to allow for an overnight ion exchange process. After exchanging for three cycles, the final product was washed with water and ethanol sufficiently and dried under vacuum. The product was denoted as Ar$\mathrm{SO}_{3} \mathrm{ZnBr}-\mathrm{MSN}$.

\subsection{Incorporation of linear imidazolium-based ionic polymers within the mesopores}

A quantitative amount of 1-vinyl-3-butylimidazolium bromide (232 $\mathrm{mg}$ ) as the monomer and AIBN (5\% relative to vinyl group) as the initiator was dissolved in a mixture of ethanol and water $(1.0 \mathrm{~mL}, 20: 80 \mathrm{v} / \mathrm{v})$. Then, the above solution was impregnated into $0.50 \mathrm{~g} \mathrm{ArSO} 3 \mathrm{ZnBr}-\mathrm{MSN}$. The yielded powder was pumped to remove the air and heated at $80{ }^{\circ} \mathrm{C}$ under $\mathrm{N}_{2}$ for $12 \mathrm{~h}$ for polymerization. It was washed with ethanol to remove the unreacted monomers and then air-dried to obtain the final product, denoted as ILP@ArSO $3 \mathrm{ZnBr}-\mathrm{MSN}$, signifying that the ionic liquid polymers (ILPs) are confined within the zinc species-anchored mesoporous silica nanospheres. To synthesize samples with different ILP contents, the dosages of 1-vinyl-3-butylimidazolium bromide monomer were changed to 150 and $350 \mathrm{mg}$, yielding L-ILP@ArSO $3 \mathrm{ZnBr}-\mathrm{MSN}$ and H-ILP@ArSO3ZnBr-MSN, respectively.

\subsection{Characterization}


Transmission electron microscopy (TEM) was performed on a JEOL-JEM-2000EX microscope. Samples for observation were prepared by dispersing the solid powder in ethanol by sonication and then allowing a drop of the suspension to evaporate on a copper gird covered with a holey carbon film. X-ray diffraction (XRD) patterns were obtained using a desktop powder X-ray diffractometer at $40 \mathrm{kV}$ and $30 \mathrm{~mA}$ with $\mathrm{Cu} K_{\alpha}$ radiation. Thermo-gravimetric analysis (TGA) was performed under an air atmosphere at a heating rate of $10{ }^{\circ} \mathrm{C} / \mathrm{min}$ on a TA SDT Q600 analyzer. Fourier transform infrared spectra (FT-IR) were obtained on a Nicolet iS5 spectrophotometer using a $\mathrm{KBr}$ pellet. Nuclear magnetic resonance (NMR) spectra were recorded on a Bruker AC 400 spectrometer using $\mathrm{CDCl}_{3}$ as the solvent. Solid-state NMR spectra were recorded on an Infinityplus $300 \mathrm{MHz}$ spectrometer. The spectra of the ${ }^{13} \mathrm{C}$ CP-MAS NMR experiments were acquired at $75.4 \mathrm{MHz}$ resonant frequency, $10.0 \mathrm{kHz}$ spin rate, $5.0 \mathrm{~s}$ pulse delay, and $1.0 \mathrm{~ms}$ contact time, using hexamethyl benzene as a reference compound. Gas chromatography-mass spectrometry (GC-MS) analysis was performed on an Agilent 7890-5977A MSD using an HP-5 column. Nitrogen-sorption analysis was carried out on a Micromeritics ASAP 2020 analyzer. Before measurement, the samples were degassed at $120^{\circ} \mathrm{C}$ under vacuum for $6 \mathrm{~h}$. The specific surface area was calculated from the adsorption branch in the relative pressure range 0.05-0.15, using the Brunauer-Emmett-Teller (BET) method, while the total pore volume was estimated from the amount adsorbed at a $P / P_{0}$ value of 0.99. Pore size distributions were determined from the adsorption branches using the Barrett-Joyner-Halenda (BJH) method.

\subsection{Procedure for the cycloaddition reaction of epoxides to form cyclic carbonates}

Typically, solid catalyst (ILP@ArSO 3 ZnBr-MSN, $100 \mathrm{mg}$ ) and PO (780 mg, $13.4 \mathrm{mmol}$ ) were charged into a $15 \mathrm{~mL}$ stainless steel reactor equipped with a magnetic stirrer. After purging with $\mathrm{CO}_{2}$ several times, the pressure was adjusted to $2 \mathrm{MPa}$, and the reactor was transferred into an oil bath to carry out the reaction at $110{ }^{\circ} \mathrm{C}$ under stirring for a certain time. Then, the reactor was cooled quickly by putting the autoclave into an ice-water bath. Subsequently, the $\mathrm{CO}_{2}$ pressure was released slowly, and the solid catalyst was separated by centrifugation. The supernatant was analyzed on an Agilent 7890 GC instrument equipped with a PEG column $(30 \mathrm{~m} \times 0.25 \mathrm{~mm} \times 0.25$ $\mathrm{mm})$. For the recycling test, the solid catalyst obtained by centrifugation was washed with ethyl acetate and dried under vacuum. Then, the catalyst was used for the subsequent cycloaddition of $\mathrm{CO}_{2}$ with PO. The same procedure was conducted four times to examine the recyclability.

\section{Results and discussion}

\subsection{Synthesis and characterization of solid hybrid catalyst}

All the steps for the synthesis of the ordered mesoporous silica decorated with dual-active-species are illustrated in Fig. 1. As shown, mesoporous silica anchored with sulfonate groups was first prepared via a prehydrolysis-induced co-condensation strategy using CTAB as the surfactant under basic conditions. During this process, 2-(4-chlorosulphonylphenyl)ethyl trichlorosilane was chosen as the co-condensed organosilane, because its chlorosulphonylphenyl group could be easily transferred in situ to the sulfonate group under the conditions of aqueous base synthesis owing to its high activity. A prehydrolysis method is utilized here because such a process is demonstrated to be helpful for introducing abundant organic groups while simultaneously maintaining the morphology of the silica materials [50]. Then, after a simple ion exchange process with overmuch $\mathrm{ZnBr}_{2}$, zinc species were anchored on the surface of mesoporous silica materials, serving as Lewis acid sites. Subsequently, the obtained host material was impregnated with 1-vinyl-3-butylimidazolium bromide monomers for the thermally induced radical polymerization, to afford ILPs within the

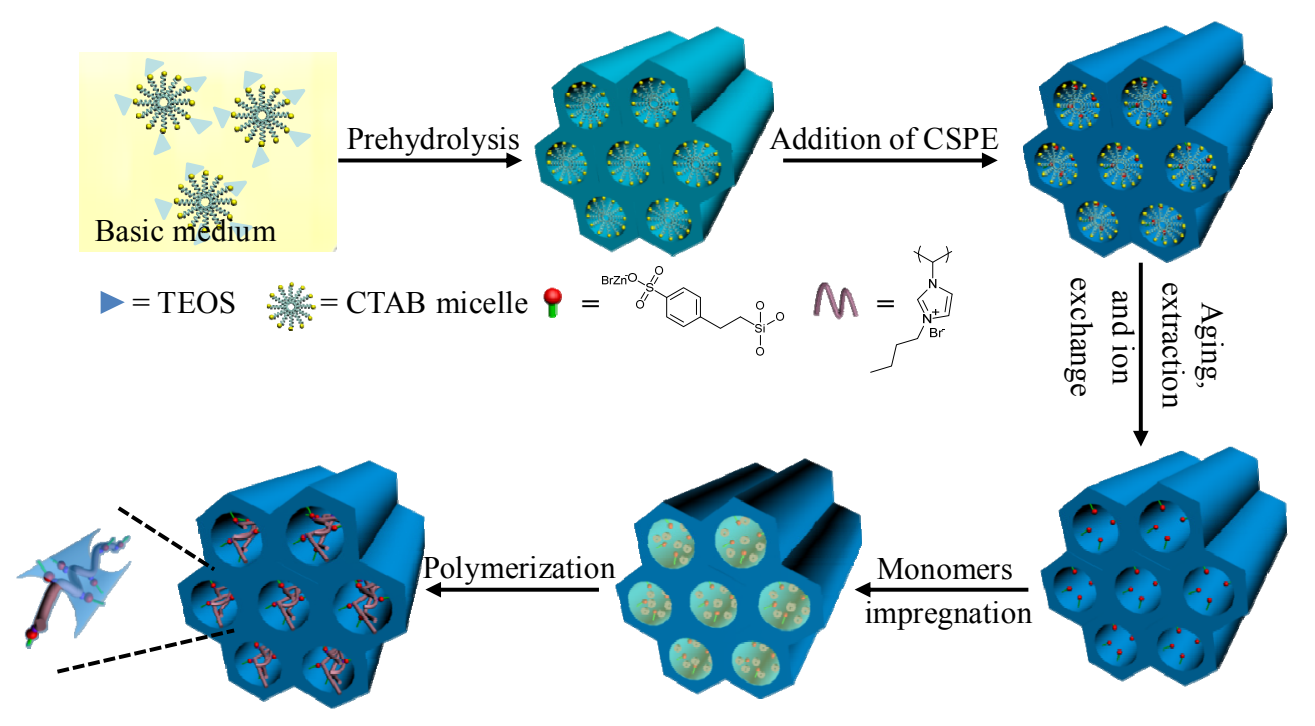

Fig. 1. Schematic illustration of the preparation of the solid catalyst decorated with Lewis acid and flexible ionic polymer dual-active-species. 
nanopores.

To verify the chemical compositions and structures of the yielded hybrid catalysts, various characterizations were performed. Fig. 2A shows that compared with the pure silica sample, MSN, the FT-IR spectrum of $\mathrm{ArSO}_{3} \mathrm{ZnBr}-\mathrm{MSN}$ not only exhibits the characteristic bands for silica around 3430, 1642, and $1086 \mathrm{~cm}^{-1}$ for $v(\mathrm{O}-\mathrm{H}), \delta(\mathrm{O}-\mathrm{H})$, and $\omega(\mathrm{Si}-0)$, respectively, but also shows typical peaks ascribable to the vibrations of organic groups, such as the $\mathrm{C}-\mathrm{H}$ stretching vibrations at 2800-2950 $\mathrm{cm}^{-1}, \mathrm{C}=\mathrm{C}$ vibration of phenyl at $1450-1540 \mathrm{~cm}^{-1}$, and the breathing vibration of the phenyl ring at $650-730 \mathrm{~cm}^{-1}$, confirming the incorporation of the -Ar groups within the mesoporous silica. The confined polymerization was confirmed from the additional peaks observed around 1160 and $1040 \mathrm{~cm}^{-1}$ arising from the imidazolium ring in ILP@ArSO 3 nBr-MSN. Stronger peaks at $2800-2950 \mathrm{~cm}^{-1}$ for the $\mathrm{C}-\mathrm{H}$ stretching vibrations were also observed, which were mainly attributable to the higher content of the organic groups. These observations demonstrated the successful incorporation of the proposed ILP into $\mathrm{ArSO}_{3} \mathrm{ZnBr}-\mathrm{MSN}$. To provide an additional proof, solid-state ${ }^{13} \mathrm{C}$ MAS NMR analysis was performed. As shown in Fig. $2 \mathrm{~B}$, the signals arising from the aromatic carbons (in the range 120-150 ppm) and $-\mathrm{CH}_{2} \mathrm{CH}_{2}-$ groups (around $30 \mathrm{ppm}$ ) are observed in $\mathrm{ArSO}_{3} \mathrm{ZnBr}-\mathrm{MSN}$, demonstrating the successful anchoring of the $-\mathrm{Ar}$ groups. For the ILP sample, the chemical shifts attributable to the carbon atoms of both the imidazolate ring (ranging from 120 to $138 \mathrm{ppm}$ ) and $\mathrm{CH}_{2}$ groups linked to the imidazole ring (ranging from 12 to $53 \mathrm{ppm}$ ) were observed. Integrating with similar signals of ILP@ArSO $3 \mathrm{ZnBr}-\mathrm{MSN}$, it is obvious that the ionic polymers are successfully incorporated. The ILP content was measured by TGA. In Fig. 2C, the weight loss below $200{ }^{\circ} \mathrm{C}$ is mainly ascribed to the physically adsorbed water, while the weight loss between 200 and $800{ }^{\circ} \mathrm{C}$ corresponds to the degradation of the organic groups. For Ar$\mathrm{SO}_{3} \mathrm{ZnBr}-\mathrm{MSN}$ and ILP@ArSO $3 \mathrm{ZnBr}^{\mathrm{MSN}}$, the weight losses due to the organic groups are calculated to be $25.8 \mathrm{wt} \%$ and 52.9 wt $\%$, respectively. The loading amount of ILP can be estimated to be about $27.1 \mathrm{wt} \%$. Notably, ILP@ArSO $3 \mathrm{ZnBr}-\mathrm{MSN}$ affords two consecutive steps of weight loss at 200 and $420{ }^{\circ} \mathrm{C}$, suggesting the uniform accommodation of ILP in the mesopores. According to the inductively coupled plasma-mass spectrometry (ICP-MS) analysis, the amount of zinc is measured to be 0.86 $\mathrm{mmol} / \mathrm{g}$, which is slightly lower than that of the $\mathrm{ArSO}_{3}-$ groups (1.15 mmol/g).

The mesostructures of the obtained materials were characterized by low angle powder XRD. It is clear from Fig. 2D that both MSN and $\mathrm{ArSO}_{3} \mathrm{ZnBr}-\mathrm{MSN}$ exhibit an intense diffraction peak assignable to the (100) reflection, along with two weak peaks corresponding to the (110) and (200) faces, suggesting that $\mathrm{ArSO}_{3} \mathrm{ZnBr}-\mathrm{MSN}$ has the same 2-D hexagonal mesostruc-
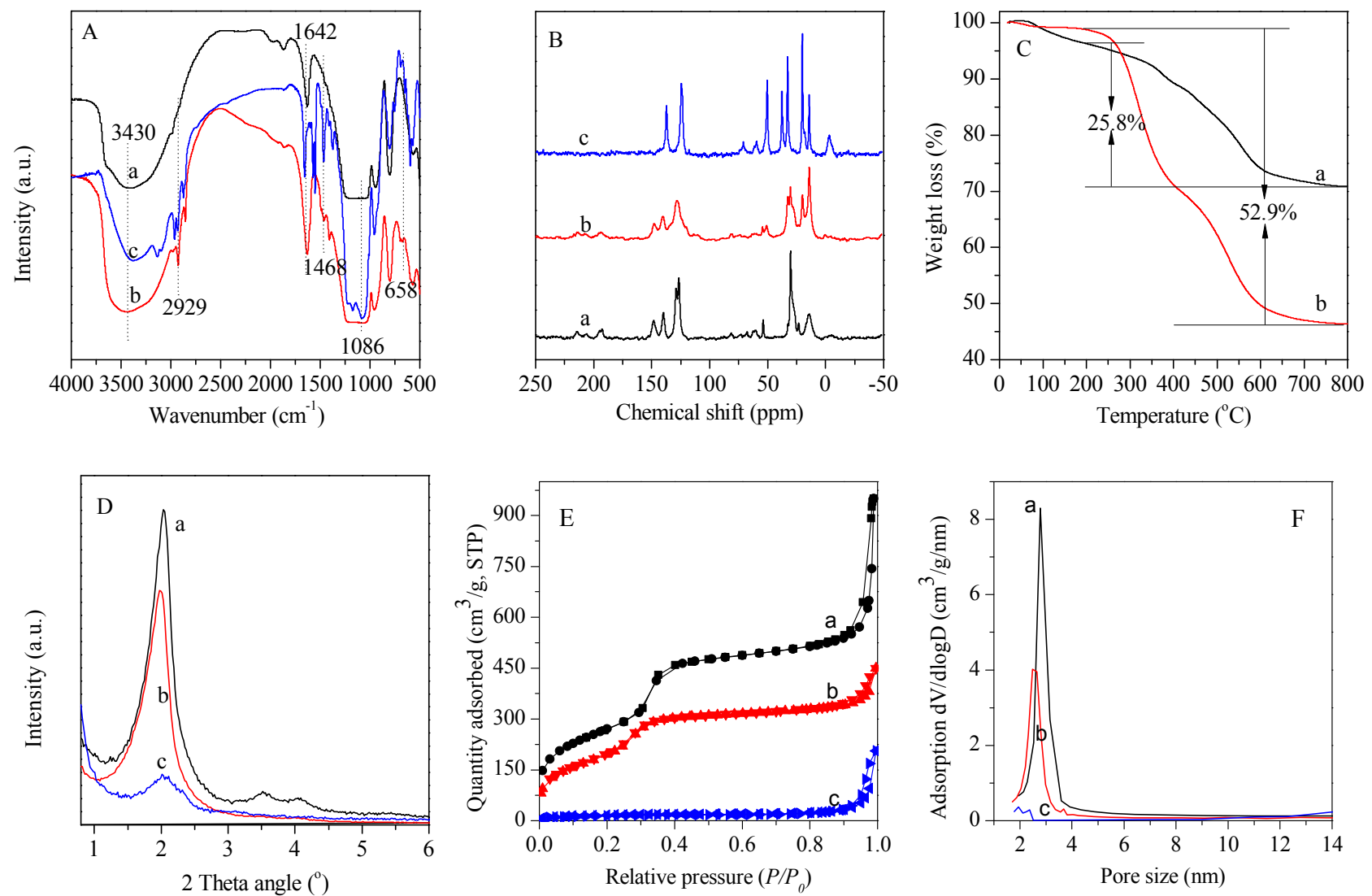

Fig. 2. (A) FT-IR spectra of (a) pure silica MSN, (b) $\mathrm{ArSO}_{3} \mathrm{ZnBr}-\mathrm{MSN}$, and (c) ILP@ArSO $3 \mathrm{ZnBr}-\mathrm{MSN}$; (B) Solid-state ${ }^{13} \mathrm{C}$ MAS NMR spectra of (a) Ar$\mathrm{SO}_{3} \mathrm{ZnBr}-\mathrm{MSN}$, (b) ILP@ArSO $\mathrm{ZnBr}-\mathrm{MSN}$, and (c) ILP obtained by etching silica; (C) TGA curves of (a) $\mathrm{ArSO}_{3} \mathrm{ZnBr}-\mathrm{MSN}$ and (b) ILP@ArSO $\mathrm{ZnBr}-\mathrm{MSN}$; (D) XRD patterns of (a) pure silica MSN, (b) $\mathrm{ArSO}_{3} \mathrm{ZnBr}-\mathrm{MSN}$, and (c) ILP@ArSO $3 \mathrm{ZnBr}-\mathrm{MSN}$; (E) Nitrogen sorption isotherms and (F) pore size distributions of (a) pure silica MSN, (b) $\mathrm{ArSO}_{3} \mathrm{ZnBr}-\mathrm{MSN}$, and (c) ILP@ArSO $3 \mathrm{ZnBr}-\mathrm{MSN}$. 
ture as MSN. ILP@ArSO $3 \mathrm{ZnBr}$-MSN exhibits a similar XRD pattern, suggesting the successful incorporation of the ordered mesoporous structure. However, after the inclusion of the ILP within the mesopores, the intensities of the corresponding diffraction peaks were weakened, indicating a disturbance in the mesostructure. The textural properties of these samples were detected by nitrogen sorption. Fig. 2E shows that MSN and Ar$\mathrm{SO}_{3} \mathrm{ZnBr}-\mathrm{MSN}$ exhibit typical type IV isotherms with a sharp capillary condensation step at relative pressures, $P / P_{0}$, of 0.2 to 0.4, which confirm their well-defined mesoporous structure. The BJH pore size distribution curves further show a uniform mesopore size centered at 2.4-2.6 nm (Fig. 2F and Table 1). Such mesopores are large enough for the following accommodation of ILP. As shown in Table 1, the BET surface area and total pore volume of $\mathrm{ArSO}_{3} \mathrm{ZnBr}-\mathrm{MSN}$ are measured to be as high as $702 \mathrm{~m}^{2} / \mathrm{g}$ and $0.69 \mathrm{~m}^{3} / \mathrm{g}$, respectively, which are slightly lower than those of MSN $\left(984 \mathrm{~m}^{2} / \mathrm{g}\right.$ and $0.97 \mathrm{~m}^{3} / \mathrm{g}$, respectively). After the incorporation of ILP, the BET surface area and pore volume of ILP@ArSO 3 ZnBr-MSN sharply decreased to 59 $\mathrm{m}^{2} / \mathrm{g}$ and $0.32 \mathrm{~m}^{3} / \mathrm{g}$, respectively. As the amount of incorporated ILP increases, the BET surface area decreases from 141 to $19 \mathrm{~m}^{2} / \mathrm{g}$ due to the dense occupancy of the ILPs in the nanopores.

The structures and morphologies of the yielded materials were further characterized by TEM. $\mathrm{ArSO}_{3} \mathrm{ZnBr}-\mathrm{MSN}$ consists of monodisperse nanoscale particles with spherical morphologies, with particle size in the range $100-200 \mathrm{~nm}$, which is similar to that of MSN (Fig. 3a and 3b). Ordered mesopores with diameter 2-3 $\mathrm{nm}$ are clearly seen from the images, suggesting the
Table 1

Textural parameters and weight losses of the synthesized silica and composite materials.

\begin{tabular}{|c|c|c|c|c|}
\hline Sample & $\begin{array}{l}\text { BET surfacel } \\
\text { area }\left(\mathrm{m}^{2} / \mathrm{g}\right)\end{array}$ & $\begin{array}{c}\text { ore volum } \\
\left(\mathrm{cm}^{3} / \mathrm{g}\right)\end{array}$ & $\begin{array}{c}\text { Pore size } \\
\mathrm{b}(\mathrm{nm})\end{array}$ & $\begin{array}{l}\text { Weight } \\
\operatorname{loss}^{\mathrm{c}}(\%)\end{array}$ \\
\hline MSN & 984 & 0.97 & 2.6 & - \\
\hline $\mathrm{ArSO}_{3} \mathrm{ZnBr}-\mathrm{MSN}$ & 702 & 0.69 & 2.4 & 25.8 \\
\hline ILP@ArSO $3 \mathrm{ZnBr}-\mathrm{MSN}$ & 59 & 0.32 & - & 52.9 \\
\hline H-ILP@ $\mathrm{ArSO}_{3} \mathrm{ZnBr-MSN}$ & 19 & 0.284 & - & 61.5 \\
\hline L-ILP@ArSO 3 ZnBr-MSN & 141 & 0.23 & 2.3 & 37.2 \\
\hline $\begin{array}{l}\text { ILP@ArSO } \mathrm{AnBr}_{3} \mathrm{ZnSN} \\
\text { (after recycling) }\end{array}$ & 135 & 0.269 & - & 47.5 \\
\hline
\end{tabular}

a Single point pore volume calculated at a relative pressure, $P / P_{0}$, of 0.99 ${ }^{b}$ Determined from adsorption branch using the BJH method. ${ }^{c}$ Weight loss between 200 and $800^{\circ} \mathrm{C}$.

mesostructured character, which has been confirmed by the XRD and nitrogen sorption analysis. No bulk ILPs were formed on the external surface of ILP@ArSO3ZnBr-MSN nanospheres, and their mesopores were indistinct from those of Ar$\mathrm{SO}_{3} \mathrm{ZnBr}-\mathrm{MSN}$ (Fig. $3 \mathrm{c}$ and $3 \mathrm{~d}$ ), demonstrating that the polymerization occurs entirely within the mesopores. To reveal the distribution of ILPs in $\mathrm{ArSO}_{3} \mathrm{ZnBr}$-MSN, HAADF-STEM was performed. As shown, uniform elemental distributions of $\mathrm{Si}, \mathrm{O}$, $\mathrm{Br}, \mathrm{N}, \mathrm{S}$, and $\mathrm{Zn}$ within the silica nanospheres are clearly observed, suggesting that the Lewis acid salts and ILPs are dispersed uniformly within the mesoporous silica material.

\subsection{Investigation of catalytic performance in the cycloaddition}
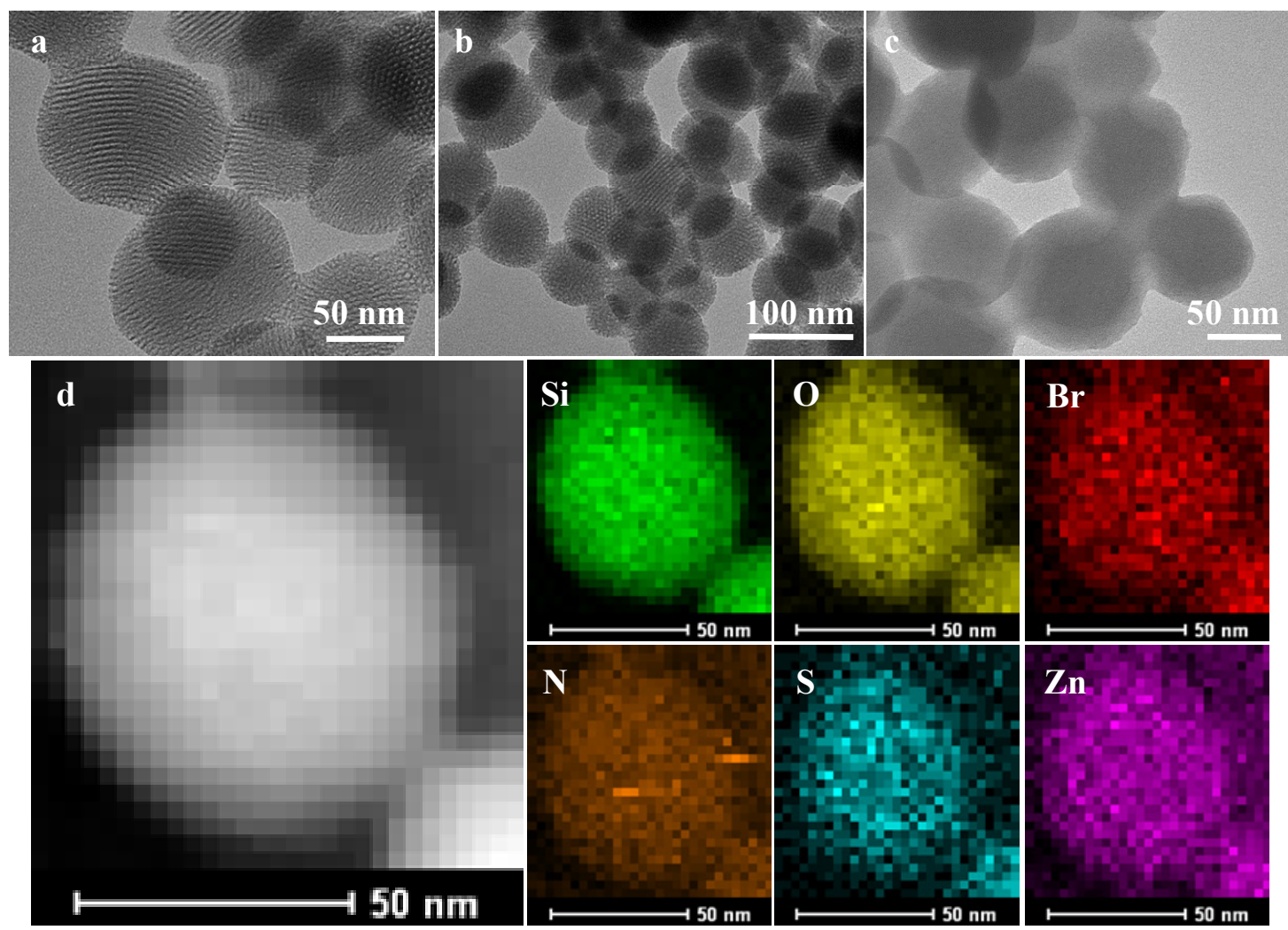

Fig. 3. TEM images of (a) MSN, (b) $\mathrm{ArSO}_{3} \mathrm{ZnBr}-\mathrm{MSN}$, and (c) ILP@ArSO $\mathrm{ZnBr}-\mathrm{MSN}$; (d) HAADF-STEM and elemental mapping images of ILP@ArSO $3 \mathrm{ZnBr}-\mathrm{MSN}$. 
reaction of epoxides

Considering the flexibility of linear ILP in ILP@ArSO $3 \mathrm{ZnBr}-\mathrm{MSN}$ and its potential cooperative ability with the anchored Lewis acid active sites (zinc species) on the silica walls and the porous structures, we set out to evaluate the catalytic performance in the cycloaddition reaction of epoxides. Encouragingly, ILP@ArSO $3 \mathrm{ZnBr}-\mathrm{MSN}$ exhibits an excellent catalytic activity, and almost complete conversion (> 99\%, Fig. 4a) could be obtained in the cycloaddition of $\mathrm{PO}$ with $2 \mathrm{MPa} \mathrm{CO}_{2}$ at $110{ }^{\circ} \mathrm{C}$, in the absence of any co-catalyst. This is comparable with the homogeneous catalytic system of IL and $\mathrm{ZnBr}$. Under identical conditions, the samples with individual active sites, $\mathrm{ArSO}_{3} \mathrm{ZnBr}-\mathrm{MSN}$ and ILP@MSN (the sample prepared through IL polymerization in pure MSN), give only $4.5 \%$ and $80 \%$ conversions, respectively. Due to the negative textural parameters of ILP@ $\mathrm{ArSO}_{3} \mathrm{ZnBr}-\mathrm{MSN}$ (BET surface area: $59 \mathrm{~m}^{2} / \mathrm{g}$, pore volume: $0.32 \mathrm{~m}^{3} / \mathrm{g}$ ), the significantly enhanced catalytic activity observed might mainly be attributed to the strengthened cooperative effects between two different catalytic components, namely $\mathrm{Br}^{-}$anions in ionic liquid (nucleophile) and the zinc species (Lewis acid). This is further supported by a control experiment using a simple physical mixture of $\mathrm{ArSO}_{3} \mathrm{ZnBr}-\mathrm{MSN}$ and ILP@MSN as a solid catalyst, in which only $83 \%$ conversion could be obtained under the same reaction conditions. The active species are spatially isolated in the last scenario, thereby leading to the obstructive contact of the two active sites. To further substantiate the cooperative effect, $\mathrm{ArSO}_{3} \mathrm{ZnBr}-\mathrm{MSN}$, together with the soluble ILP component, were used to catalyze the reaction. An enhanced activity was observed, and 96\% conversion was achieved. However, it is still slightly lower than that in ILP@ $\mathrm{ArSO}_{3} \mathrm{ZnBr}-\mathrm{MSN}$. This is easy to understand. In the dissolved state, the free mobility of the linear ILP species ena- bles the nuclephile ( $\mathrm{Br}^{-}$ions) and Lewis acid sites to work synergistically, thus facilitating the reactions. However, a portion of ILP is distributed in the solution and will not participate in the cooperative catalytic reaction, thus resulting in a relative lower utilization efficiency. However, in ILP@ArSO $32 n B r-M S N$, almost all the ILP components are dispersed in the vicinity of the zinc species within the nano-confined spaces; therefore, the chances of cooperative processes between the two different types of catalytic components are increased significantly, leading to higher activity. These observations also highlight the superiority of our in situ polymerization method, through which the ILP are confined homogeneously in the mesopores. Nevertheless, the obtained catalytic performances are not so impressive compared with some of those reported in the literature (listed in Table S1). This might be ascribed to the compact structure and low surface area of the solid catalyst.

For further investigating the catalytic performance of ILP@ArSO $3 \mathrm{ZnBr}-\mathrm{MSN}$, the reaction kinetics were recorded. Fig. $4 \mathrm{~b}$ shows that the cycloaddition of $\mathrm{PO}$ proceeds smoothly as the reaction time increases, demonstrating the excellent catalytic activity. The influence of the ionic polymer content on the catalytic performance of the ILP@ArSO 3 ZnBr-MSN catalysts was also investigated (Table 2). As evident, on increasing the polymer content, the activity of the composite catalyst increased gradually. For H-ILP@ArSO $3 \mathrm{ZnBr-MSN}$ with a high ILP loading, complete conversion was obtained within $3 \mathrm{~h}$, while a longer time of $5 \mathrm{~h}$ was needed for L-ILP@ArSO $3 \mathrm{ZnBr}-\mathrm{MSN}$. The influences of reaction conditions, such as the amounts of catalyst, temperature, and $\mathrm{CO}_{2}$ pressure, were also investigated. Table 2 shows that a longer time of up to $5 \mathrm{~h}$ was needed to complete the reaction when the amount of solid catalyst was decreased to $50 \mathrm{mg}$. However, the reaction was already over within $1.5 \mathrm{~h}$ as the amount of solid catalyst was increased to $200 \mathrm{mg}$. On
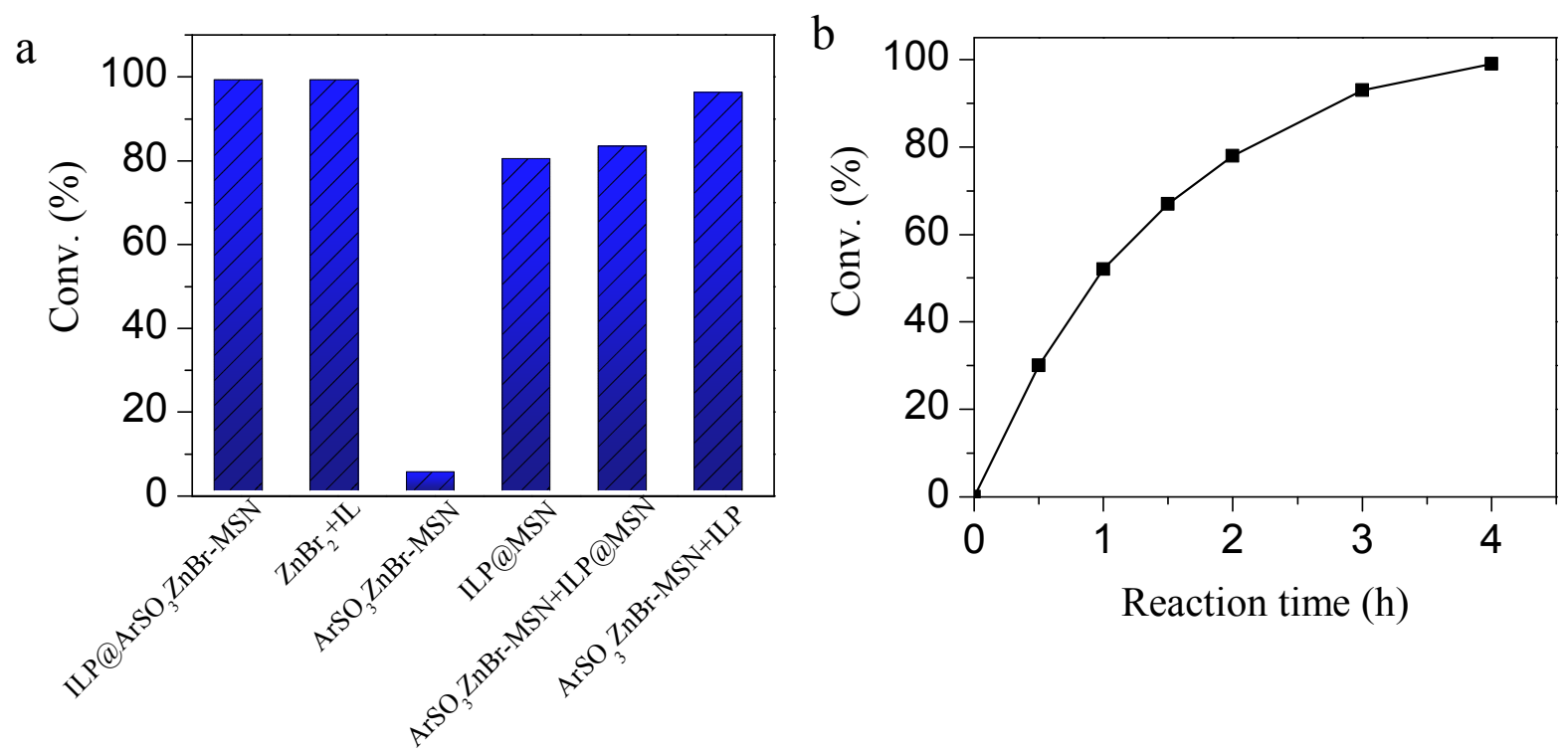

Fig. 4. (a) Catalytic conversion of $\mathrm{CO}_{2}$ cycloaddition with $\mathrm{PO}$ over different catalysts; (b) Kinetic profile of the cycloaddition reaction between pure $\mathrm{CO}_{2}$ and PO catalyzed by ILP@ArSO $3 \mathrm{ZnBr}-\mathrm{MSN}$. Reaction conditions: PO (780 mg, $13.4 \mathrm{mmol}$ ), 2 MPa CO2, $110{ }^{\circ} \mathrm{C}, 4$ h. Catalysts: 100 mg ILP@ Ar$\mathrm{SO}_{3} \mathrm{ZnBr}-\mathrm{MSN}$ (containing $0.086 \mathrm{mmol}$ zinc and $0.117 \mathrm{mmol} \mathrm{IL}$ ), $19.3 \mathrm{mg}$ of $\mathrm{ZnBr}_{2}+27.1 \mathrm{mg}$ of IL (0.086 mmol zinc and $0.117 \mathrm{mmol}$ IL), $100 \mathrm{mg}$ Ar$\mathrm{SO}_{3} \mathrm{ZnBr}-\mathrm{MSN}, 100 \mathrm{mg}$ of ILP@MSN, a mixture of 100 mg of $\mathrm{ArSO}_{3} \mathrm{ZnBr}-\mathrm{MSN}$ and ILP@MSN, and $100 \mathrm{mg}$ of ArSO $3 \mathrm{ZnBr}-\mathrm{MSN}+27.1 \mathrm{mg}$ of ILP. 

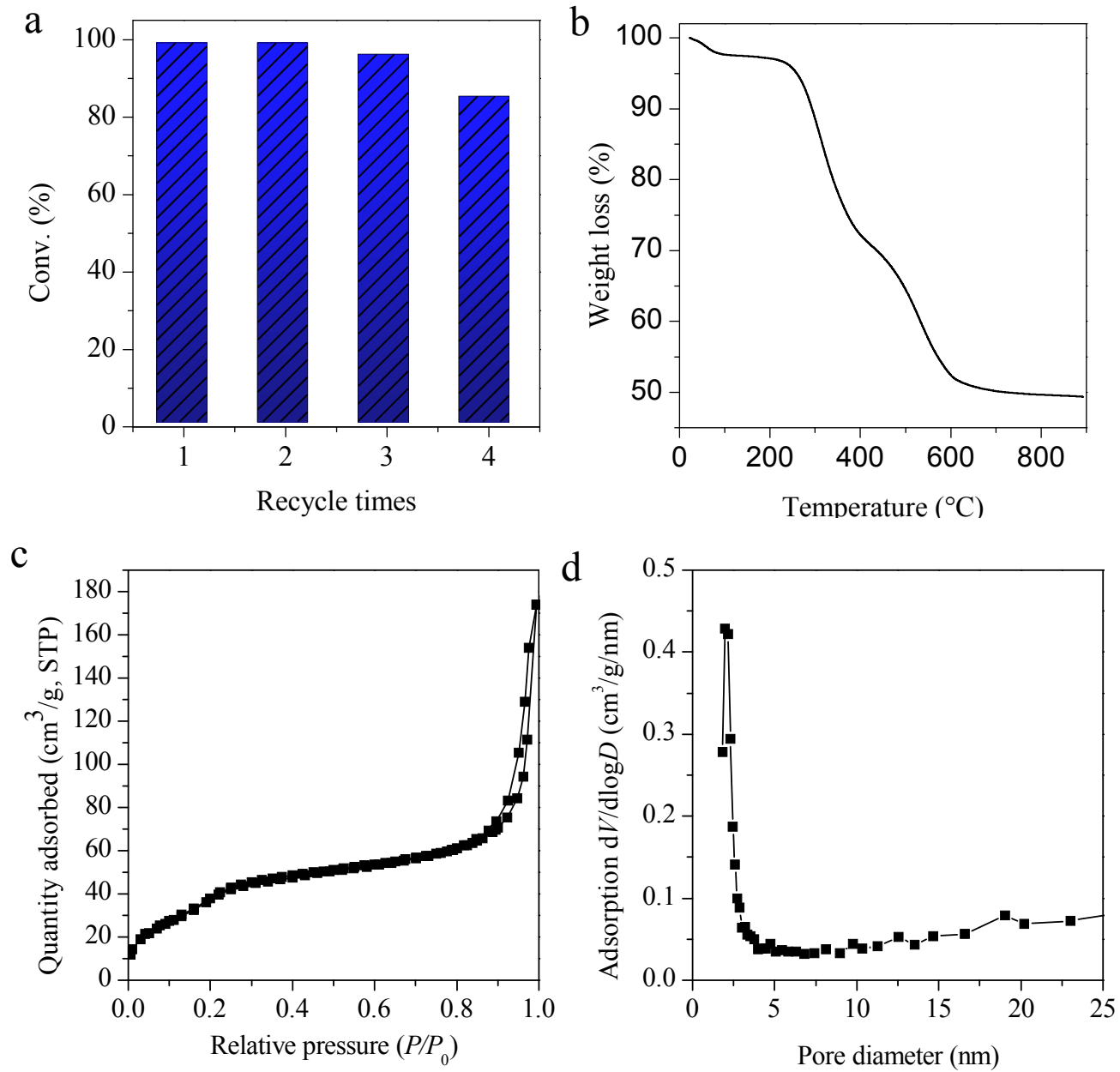

Fig. 5. (a) Recycling test of ILP@ArSO 3 ZnBr-MSN; (b) TGA curve of the recycled solid catalyst; (c) and (d) Nitrogen sorption characterization of the recycled catalyst.

raising the reaction temperature from 45 to $130{ }^{\circ} \mathrm{C}$, the reaction rate increased significantly. For example, the $\mathrm{PO}$ substrate could be completely converted within $2 \mathrm{~h}$ at $130{ }^{\circ} \mathrm{C}$, while $94.6 \%$ and $97 \%$ conversions were achieved within 24 and $7 \mathrm{~h}$ at 45 and $90{ }^{\circ} \mathrm{C}$, respectively. Notably, when the $\mathrm{CO}_{2}$ pressure was changed to $1 \mathrm{MPa}, 96 \%$ conversion could still be achieved within $7 \mathrm{~h}$, further demonstrating the good efficiency of the solid catalyst.

Encouraged by the above results, we then investigated the recycling stability under the same reaction conditions, which is an important feature of a heterogeneous catalyst [51]. After the reaction, the solid catalyst was separated by simple centrifugation and used directly for the next cycle. Remarkably, ILP@ArSO $32 \mathrm{ZnB}-\mathrm{MSN}$ could be readily recycled for at least four cycles, highlighting its heterogeneous nature (Fig. 5a). This is interesting because the absence of covalent bonds between the mesoporous silica and ILP might result in the leaching of ILP from the solid catalyst during the reaction. The remarkable stability might originate from the existing twining effect of the linear polymers within the nanoporous scaffold. This is further verified by the low amount of leached ILP after treating the solid catalyst under harsh conditions (Fig. S1). However, the conversion decreased to $85 \%$ in the fourth cycle. For exploring the causes of the decreased activity, the zinc species were detected using ICP, and it was found that $5.8 \%$ zinc was present in the reaction solution. To further investigate the cause of deactivation, nitrogen sorption and TG measurements of the recycled catalyst were conducted (Fig. 5b-d). After the recycling tests, the solid catalyst exhibited slightly larger BET surface area and comparable pore volume as compared with the fresh catalyst (Table 1, 135 vs $59 \mathrm{~m}^{2} / \mathrm{g}$ and 0.269 vs $0.32 \mathrm{~m}^{3} / \mathrm{g}$, respectively). This might resulted from the partial escape of ILP from the nanopores. Although TGA characterization demonstrated that only a small quantity of ILP was leached from the solid catalyst ( $47.5 \%$ vs $52.9 \%$ ), the partial escape of ILP reduced the chances of contact between the two cooperative species. Therefore, the decreased activity might be related to the diminished cooperative effects.

Based on the outstanding performance of ILP@ArSO $3 \mathrm{ZnBr}-\mathrm{MSN}$ in the $\mathrm{CO}_{2}$ cycloaddition with PO, the reactions with other epoxides were studied (the corresponding products were determined by GC-MS and NMR, see Supporting Information). As listed in Table 2, excellent conversions were obtained in almost all the reactions under the test conditions, including those of terminal epoxides with both electron-withdrawing and electron-donating substituents. An ex- 
Table 2

ILP@ArSO $3 \mathrm{ZnBr}-\mathrm{MSN}$-catalyzed $\mathrm{CO}_{2}$ cycloaddition with epoxides substituted with different functional groups ${ }^{\text {a }}$.

\begin{tabular}{|c|c|c|c|c|c|}
\hline Entry & Substrate & Product & $\begin{array}{l}\text { Time } \\
\text { (h) }\end{array}$ & $\begin{array}{c}\text { Conversion } \\
\text { (isolated } \\
\text { yield) }{ }^{\mathrm{b}}(\%)\end{array}$ & $\begin{array}{c}\text { Selec- } \\
\text { tivity } \\
(\%) \\
\end{array}$ \\
\hline \multirow[t]{9}{*}{1} & & & 4 & $>99(92)$ & $>99$ \\
\hline & & & $5^{c}$ & 99 & $>99$ \\
\hline & & & $3^{d}$ & $>99$ & $>99$ \\
\hline & & & $5^{e}$ & 99 & $>99$ \\
\hline & & & $1.5^{\mathrm{f}}$ & $>99$ & $>99$ \\
\hline & & & $24 \mathrm{~g}$ & 94.6 & $>99$ \\
\hline & & & $7_{\mathrm{h}}^{\mathrm{h}}$ & 97 & $>99$ \\
\hline & & & $2^{\mathrm{i}}$ & $>99$ & $>99$ \\
\hline & & & $7 \mathrm{j}$ & 96 & $>99$ \\
\hline 2 & & & 7 & $>99(95)$ & $>99$ \\
\hline 3 & & & 10 & $>99$ (97) & $>99$ \\
\hline 4 & & & 24 & 40 (37) & $>99$ \\
\hline 5 & & & 6 & $>99$ (99) & $>99$ \\
\hline 6 & & & 10 & $>99(97)$ & $>99$ \\
\hline 7 & & & 7 & $>99(99)$ & $>99$ \\
\hline \multicolumn{6}{|c|}{ 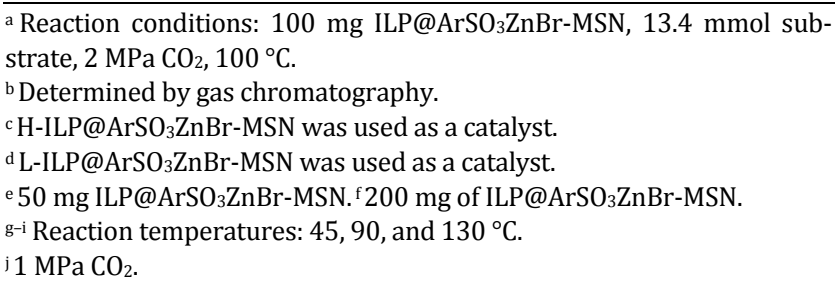 } \\
\hline
\end{tabular}

ceptionally low conversion (40\%) was achieved for cyclohexene oxide even at longer reaction times, which might result from the much larger steric hindrance of cyclohexene oxide compared with that of other terminal epoxides. These results indicate that the composite catalyst can be broadly used in such reactions.

On the basis of some previous reports $[12,37,39,52]$ and combining the dual-active species-anchored structure of the solid ILP@ArSO $\mathrm{ZnBr}-\mathrm{MSN}$ catalyst and the observed catalytic performance, a possible intramolecular synergistic mechanism involving the Lewis acidic zinc species and nucleophilic $\mathrm{Br}^{-}$is proposed for the $\mathrm{CO}_{2}$ cycloaddition of epoxides to form cyclic carbonates. As illustrated in Fig. 6, the oxygen atom of the diffused epoxide first binds to the coordinatively unsaturated zinc

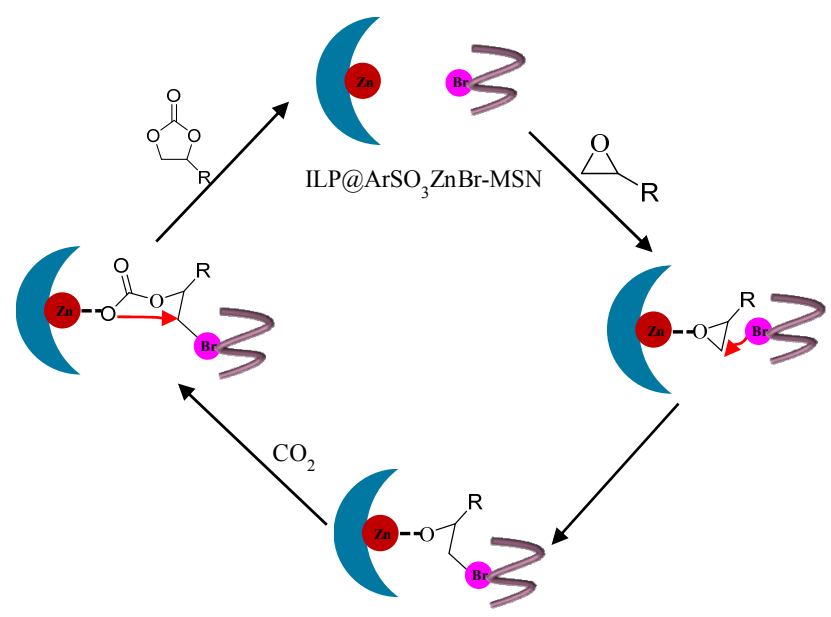

Fig. 6. Proposed mechanism for the cycloaddition of epoxide and $\mathrm{CO}_{2}$ over ILP@ArSO $3 \mathrm{ZnBr}-\mathrm{MSN}$.

sites (Lewis acid) that is dispersed on the silica wall, forming $\mathrm{Zn}-\mathrm{O}$ coordination bond. This leads to the activation of the epoxy ring. Simultaneously, the nucleophilic $\mathrm{Br}^{-}$in ILP attacks the less-hindered carbon atom of the activated epoxide at an appropriate angle. This process promotes the opening of the epoxy ring, affording an intermediate $\mathrm{Zn}$-coordinated bromo alkoxide. Subsequently, $\mathrm{CO}_{2}$ inserts into the open epoxy ring to form a zinc carbonate intermediate. Finally, the reaction reaches completion through an intramolecular cyclization of the acyclic ester, resulting in the formation of the desired cyclic carbonate and regeneration of the solid catalyst.

\section{Conclusions}

In summary, a dual-active species-based cooperative solid catalyst was constructed successfully by confining a linear imidazolium-based ionic polymer in the mesopores of the ordered mesoporous silica nanospheres that were pre-anchored with zinc species. Due to the strengthened synergistic activation of the active metal center and halogen anion, such a catalyst exhibited excellent activity in the cycloaddition reaction of the epoxides to form cyclic carbonates. Moreover, the catalyst could be easily separated and reused several times by a simple method of centrifugation. Because of the diversity of both the mesoporous host and the ionic polymer guest, this work might provide a novel avenue for the development of heterogeneous catalysts with integrated superior properties for other reactions.

\section{References}

[1] Q. Liu, L. P. Wu, R. Jackstell, M. Beller, Nat. Commun., 2015, 6, 5933.

[2] M. Aresta, A. Dibenedetto, A. Angelini, Chem. Rev., 2014, 114, 1709-1742.

[3] C. Martín, G. Fiorani, A. W. Kleij, ACS Catal., 2015, 5, 1353-1370.

[4] A. J. Hunt, E. H. K. Sin, R. Marriott, J. H. Clark, ChemSusChem, 2010, 3, 306-322. 


\section{Graphical Abstract}

Chin. J. Catal., 2019, 40: 1874-1883 doi: S1872-2067(19)63340-1

\section{Incorporation of flexible ionic polymers into a Lewis acid-functionalized mesoporous silica for cooperative conversion of $\mathrm{CO}_{2}$ to cyclic carbonates}

Ruqun Guan, Xiaoming Zhang*, Fangfang Chang, Nan Xue, Hengquan Yang* Shanxi University

Flexible ionic polymers were confined in the nanopores of a Lewis acid-functionalized mesoporous silica for facilitating the cooperative effects and accelerating the catalytic activity in the cycloaddition of $\mathrm{CO}_{2}$ with epoxides.

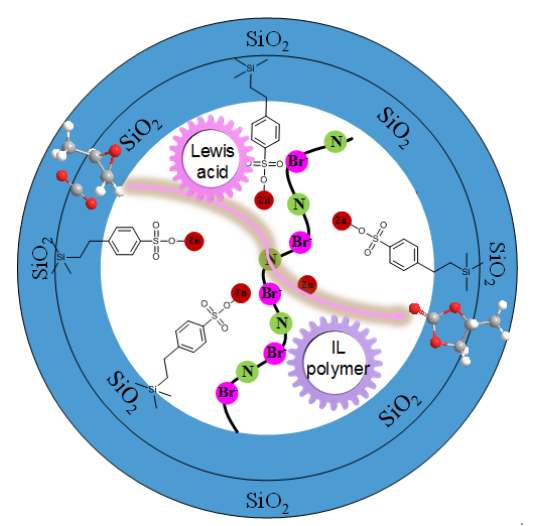

2589-2594.

[5] H. Büttner, L. Longwitz, J. Steinbauer, C. Wulf, T. Werner, Top. Curr. Chem., 2017, 375, 50.

[6] R. R. Shaikh, S. Pornpraprom, V. D’Elia, ACS Catal., 2018, 8, 419-450.

[7] A. Decortes, A. M. Castilla, A. W. Kleij, Angew. Chem. Int. Ed., 2010, 49, 9822-9837.

[8] T. Ema, Y. Miyazaki, J. Shimonishi, C. Maeda, J. Hasegawa, J. Am. Chem. Soc., 2014, 136, 15270-15279.

[9] V. D'Elia, H. l. Dong, A. J. Rossini, C. M. Widdifield, Sai V. C. Vummaleti, Y. Minenkov, A. Poater, E. Abou-Hamad, J. D. A. Pelletier, L. Cavallo, L. Emsley, J. M. Basset, J. Am. Chem. Soc., 2015, 137, 7728-7739.

[10] A. Barthel, Y. Saih, M. Gimenez, J. D. A. Pelletier, F. E. Kühn, V. D’Elia, J. M. Basset, Green Chem., 2016,18, 3116-3123.

[11] L. H. Yang, H. M. Wang, ChemSusChem, 2014, 7, 962-998.

[12] B. H. Xu, J. Q. Wang, J. Sun, Y. Huang, J. P. Zhang, X. P. Zhang, S. J. Zhang, Green Chem., 2015, 17, 108-122.

[13] F. W. Li, L. F. Xiao, C. G. Xia, B. Hu, Tetrahedron Lett, 2004, 45, 8307-8310.

[14] K. Wu, T. Su, D. M. Hao, W. P. Liao, Y. C. Zhao, W. Z. Ren, C. L. Deng, H. Y. Lv, Chem. Commun., 2018, 54, 9579-9582.

[15] M. North, B. D. Wang, C. Young, Energy Environ. Sci., 2011, 4, 4163-4170.

[16] O. V. Zalomaeva, A. M. Chibiryaev, K. A. Kovalenko, O. A. Kholdeeva, B. S. Balzhinimaev, V. P. Fedin, J. Catal., 2013, 298, 179-185.

[17] C. A. Trickett, A. Helal, B. A. Al-Maythalony, Z. H. Yamani, K. E. Cordova, O. M. Yaghi, Nat. Rev. Mater., 2017, 2, 17045.

[18] H. M. He, J. A. Perman, G. S. Zhu, S. Q. Ma, Small, 2016, 12, 6309-6324.

[19] K. Huang, J. Y. Zhang, F. J. Liu, S. Dai, ACS Catal,, 2018, 8, 9079-9102.

[20] Y. Xie, T. T. Wang, X. H. Liu, K. Zou, M. W. Q. Deng, Nat. Commun., 2013, 4, 1960.

[21] J. Chen, M. M. Zhong, L. Tao, L. N. Liu, S. Jayakumar, C. Z. Li, H. Li, Q. H. Yang, Green Chem., 2018, 20, 903-911.

[22] X. Y. Ma, B. Zou, M. H. Cao, S. L. Chen, C. W. Hu, J. Mater. Chem. A, 2014, 2, 18360-18366.

[23] F. D. Bobbink, D. Vasilyev, M. Hulla, S. Chamam, F. Menoud, G. Laurenczy, S. Katsyuba, P. J. Dyson, ACS Catal., 2018, 8,
[24] G. K. Cui, J. J. Wang, S. J. Zhang, Chem. Soc. Rev., 2016, 45, 4307-4339.

[25] Z. Z. Yang, Y. N. Zhao, L. N. He, RSC Adv., 2011, 1, 545-567.

[26] F. D. Bobbink, P. J. Dyson, J. Catal., 2016, 343, 52-61.

[27] X. P. Zhang, X. C. Zhang, H. F. Dong, Z. J. Zhao, S. J. Zhang, Y. Huang, Energy Environ. Sci., 2012, 5, 6668-6681.

[28] M. V. Zakharova, F. Kleitz, F. G. Fontaine, ChemCatChem, 2017, 9, 1886-1890.

[29] X. F. Wang, N. G. Akhmedov, Y. H. Duan, D. Luebke, B. Y. Li, J. Mater. Chem. A, 2013, 1, 2978-2982.

[30] Q. Su, Y. Q. Qi, X. Q. Yao, W. G. Cheng, L. Dong, S. S. Chen, S. J. Zhang, Green Chem., 2018, 20, 3232-3241.

[31] W. Zhang, Q. X. Wang, H. L. Wu, P. Wu, M. Y. He, Green Chem., 2014, $16,4767-4774$.

[32] X. C. Wang, Y. Zhou, Z. J. Guo, G. J. Chen, J. Li, Y. M. Shi, Y. Q. Liu, J. Wang, Chem. Sci., 2015, 6, 6916-6924.

[33] Y. Liu, W. G. Cheng, Y. Q. Zhang, J. Sun, S. J. Zhang, Green Chem., 2017, 19, 2184-2193.

[34] W. L. Wang, C. Y. Li, L. Yan, Y. Q. Wang, M. Jiang, Y. J. Ding, ACS Catal., 2016, 6, 6091-6100.

[35] M. L. Ding, H. L. Jiang, ACS Catal., 2018, 8, 3194-3201.

[36] B. Aguila, Q. Sun, X. L. Wang, E. O’Rourke, A. M. Al-Enizi, A. Nafady, S. Q. Ma, Angew. Chem. Int. Ed., 2018, 57, 10107-10111.

[37] Q. Sun, B. Aguila, J. A. Perman, N. T. K. Nguyen, S. Q. Ma, J. Am. Chem. Soc., 2016, 138, 15790-15796.

[38] S. Jayakumar, H. Li, L. Tao, C. Z. Li, L. N. Liu, J. Chen, Q. H. Yang, ACS Sustainable Chem. Eng., 2018, 6, 9237-9245.

[39] Y. J. Chen, R. C. Luo, Q. H. Xu, J. Jiang, X. T. Zhou, H. B. Ji, ChemSusChem, 2017, 10, 2534-2541.

[40] W. L. Wang, Y. Q. Wang, C. Y. Li, L. Yan, M. Jiang, Y. J. Ding, ACS Sustainable Chem. Eng., 2017, 5, 4523-4528.

[41] C. Y. Li, W. L. Wang, L. Yan, Y. Q. Wang, M. Jiang, Y. J. Ding, J. Mater. Chem. A, 2016, 4, 16017-16027.

[42] B. Li, S. Y. Bai, X. F. Wang, M. M. Zhong, Q. H. Yang, C. Li, Angew. Chem. Int. Ed., 2012, 51, 11517-11521.

[43] H. Chang, Q. S. Li, X. M. Cui, H. X. Wang, C. Z. Qiao, Z. W. Bu, T. Lin, Mol. Catal., 2018, 449, 25-30.

[44] L. Y. Jing, X. M. Zhang, R. Q. Guan, H. Q. Yang, Catal. Sci. Technol., 2018, 8, 2304-2311. 
[45] J. Wei, Z. K. Sun, W. Luo, Y. H. Li, A. A. Elzatahry, A. M. Al-Enizi, Y. H. Deng, D. Y. Zhao, J. Am. Chem. Soc., 2017, 139, 1706-1713.

[46] J. Liu, S. Z. Qiao, J. S. Chen, X. W. Lou, Chem. Commun., 2011, 47, 12578-12591.

[47] T. Y. Cheng, Q. K. Zhao, D. C. Zhang, G. H. Liu, Green Chem., 2015, $17,2100-2122$.

[48] X. M. Zhang, S. M. Lu, M. M. Zhong, Y. P. Zhao, Q. H. Yang, Chin. J. Catal., 2015, 36, 168-174.
[49] Y. Xie, Z. F. Zhang, T. Jiang, J. L. He, B. X. Han, T. B. Wu, K. L. Ding, Angew. Chem. Int. Ed., 2007, 46, 7255-7258.

[50] J. Peng, Y. Yao, X. M. Zhang, C. Li, Q. H. Yang, Chem. Commun., 2014, 50, 10830-10833.

[51] W. L. Wang, L. F. Cui, P. Sun, L. J. Shi, C. T. Yue, F. W. Li, Chem. Rev., 2018, 118, 9843-9929.

[52] L. F. Xiao, F. W. Li, J. J. Peng, C. G. Xia, J. Mol. Catal. A, 2006, 253, 265-269.

\title{
Lewis酸功能化介孔氧化硅限域柔性离子液聚合物协同催化 $\mathrm{CO}_{2}$ 与环氧化合物环加成反应
}

\author{
关茹群, 张晓明", 常芳芳, 薛 楠, 杨恒权 ${ }^{\#}$ \\ 山西大学化学化工学院, 山西太原030006
}

\begin{abstract}
摘要: 二氧化碳与环氧化物通过环加成制备环状碳酸酯是一个典型的“原子经济”和“绿色化学”反应, 也是二氧化碳化学法 利用最为有效的途径之一. 离子液体催化剂因其独特的物理化学性质及催化活性, 是该反应最常见和最有效的催化剂类 型之一. 然而, 由于该反应为双组分协同作用机制, 在催化反应过程中, 通常要加入路易斯酸作为助催化剂来进攻环氧化 合物上的氧原子, 促进开环反应. 因此, 设计合成双组分在空间上能够相互接近的催化剂对促进协同效应, 获得高活性催 化剂至关重要.

本文利用介孔氧化硅材料表面易修饰、比表面积高和孔道易引入客体单元的特性, 首先以阳离子表面活性剂CTAB为 模板, 通过预缩聚的策略将磺酸根基团引入到孔道表面, 与 $\mathrm{ZnBr}_{2}$ 进行离子交换后, 得到Lewis酸功能化的介孔氧化硅材料. 然后, 通过浸渍和热引发自由基聚合的方法将咪唑基线性离子液聚合物引入到材料孔道内, 得到孔道限域离子液柔性聚合 物和表面镶嵌Lewis酸单元的双组分催化剂. 由于介孔孔道的空间限域作用和柔性聚合物的半“自由”性, 在纳米尺度空间 内可增强两种活性组分间的协同催化性能. 在环氧丙烷的环加成反应中 $\left(110^{\circ} \mathrm{C}\right.$ 和 $2 \mathrm{MPa} \mathrm{CO}_{2}$ 条件下), 所制备的双组分催 化剂(转化率和选择性 $>99 \%$ ) 表现出优于单组分催化剂(转化率分别为 $4.5 \%$ 和 $80 \%$ )和单组分催化剂混合物(转化率 $83 \%$ )的 反应活性. 同时, 在相同反应条件下, 向Lewis酸功能化氧化硅材料中后加入聚合离子液的反应体系转化率为 $96 \%$, 相较原 位引入聚合离子液的方法仍有差距, 这主要是由于离子液聚合物不能完全进入到孔道与Lewis酸中心接触造成的. 因此, 所 制备的双组分催化剂的优异性能可能与增强的协同催化能力相关. 由于聚合物链的缠绕作用和介孔孔道的限域作用, 该 双组分催化剂也具有较好的循环使用性能, 循环使用 4 次后仍能得到 $85 \%$ 的转化率. 该研究进一步揭示了利用纳米孔限域 空间可促进多组分位点协同催化, 可能拓展至其它协同型催化剂的制备与应用.
\end{abstract}

关键词: 介孔氧化硅; 柔性离子液聚合物; 协同效应; 二氧化碳转化; 多相催化

收稿日期: 2019-02-05. 接受日期: 2019-03-25. 出版日期: 2019-12-05.

*通讯联系人. 电话: (0351)7011588; 传真: (0351)7011688; 电子信箱: xmzhang4400@sxu.edu.cn

\#通讯联系人. 电话: (0351)7011588; 传真: (0351)7011688; 电子信箱: hqyang@sxu.edu.cn

基金来源：国家自然科学基金(201573136, 21603128, U1510105); 山西省青年科技研究基金(2016021034); 山西大学人才事业启 动经费(RSC723).

本文的电子版全文由Elsevier出版社在ScienceDirect上出版(http://www.sciencedirect.com/science/journal/18722067). 